\title{
Citrus bergamia Extract
}

National Cancer Institute

\section{Source}

National Cancer Institute. Citrus bergamia Extract. NCI Thesaurus. Code C107291.

The oil extracted from the fruit peel of Citrus berg amia. Bergamot oil is used in the treatment of psoriasis, mycosis fungoides, and vitiligo. Additionally, it is used as a citrus flavoring agent. 